\title{
EUROPEAN SPINE JOURNAL MAX AEBI AWARD FOR CLINICAL SCIENCES 2018/2019
}

\section{ORIGINAL ARTICLE}

\section{The impact and value of uni- and multimodal intraoperative neurophysiological monitoring (IONM) on neurological complications during spine surgery: a prospective study of 2728 patients}

Martin Sutter ${ }^{1} \cdot$ Andreas Eggspuehler $^{1} \cdot$ Dezsoe Jeszenszky ${ }^{2} \cdot$ Frank Kleinstueck $^{2} \cdot$ Tamàs F. Fekete $^{2}$. Daniel Haschtmann ${ }^{2}$ - François Porchet ${ }^{2}$ - Jiri Dvorak ${ }^{1}$

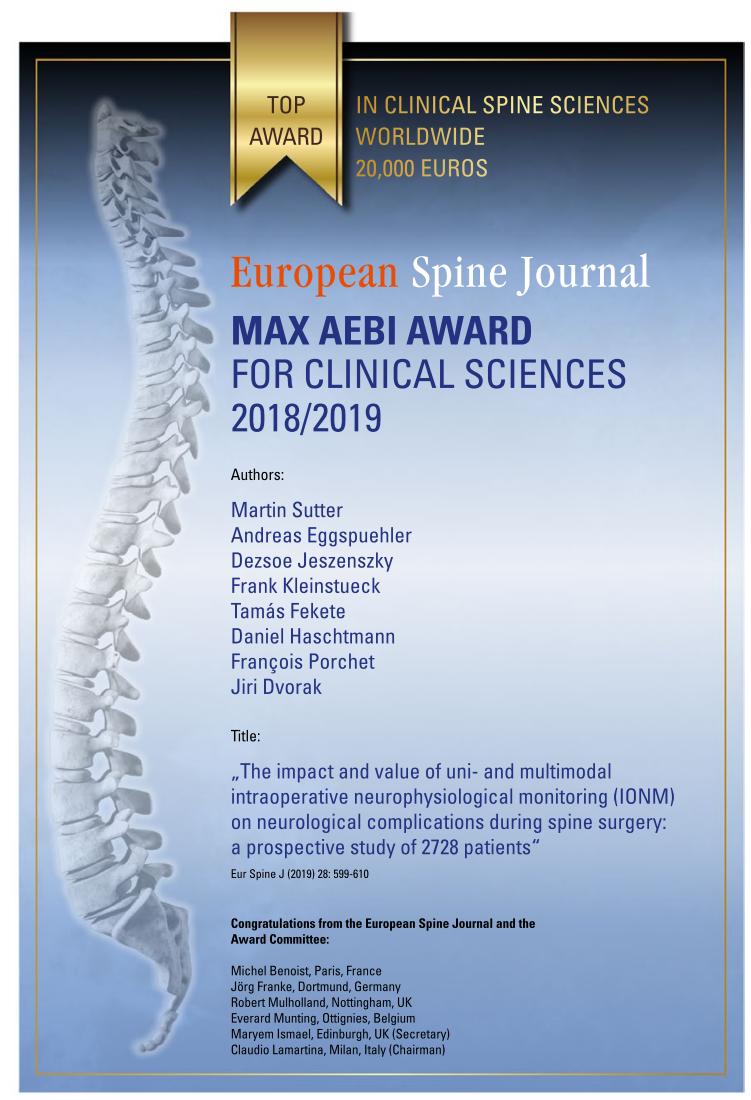

The online version of the original article can be found under https://doi.org/10.1007/s00586-018-5861-0. 